\title{
Antibiotic Susceptibility Profile and Prevalence of AmpC among Clinical Bacterial Isolates obtained From Northwestern Nigeria
}

\author{
Shu'aibu, S.S., Arzai A.H. and Mukhtar, M.D. \\ Department of Microbiology Bayero University, Kano \\ shuaibusameera@gmail.com: 08118765254
}

\begin{abstract}
Antibiotic Resistance is spreading all over the world conferring multiple resistant in the treatment and management of life threatening infections. Cephalosporins are antibiotics prescribed daily for a wide variety of infections in Nigerian hospitals. The production of bla-AmpC enzymes by many Enterobacteriaceae conferred resistance to such class of antibiotics. The aim of the study is to determine the antibiotic susceptibility and prevalence of AmpC among clinical bacterial isolates obtained from Northwestern Nigeria. A total of 1000 clinical bacterial isolates were collected from seven states of north western Nigeria and were screened Phenotypically for AmpC production using Disk Approximation test. Antibiotic sensitivity test was performed according to clinical and laboratory standard Institutes guidelines (CLSI). Acinetobacter baumanii, Serratia liquefaciens and Providence sp showed 100\% resistance to third generation cephalosporin antibiotics as well as Levofloxacin, Impinem and Tigercycline, moderate susceptibility was observed with Colistin, followed by Proteus Mirabilis (85\%) resistance to Ceftizoxime. Tigercycline and Colistin were the most active drugs against the Isolates. The prevalence of AmpC production among the isolates showed that Acinetobacter baumanii, Aeromonas sp., Providence sp., Serratia liquefaciens and Citrobacter freundi had the highest prevalence of $100 \%$ each. Enterobacter clocae had least value of 50\%. Similarly, high Multi-Drug Resistance (MDR) $100 \%$ was shown by $A$. baumannii, Aeromonas sp, Providence $s p$ and $S$. liquefaciens with least values from Staphylococcus aureus (33.1\%). The occurrence of AmpC was higher among male patients with prevalence rate of $54.1 \%, p$-value $>0.001$. The occurrence of these resistance conferring enzymes was chronologically sensitive as its prevalence is more pronounced among patients aged $>60$ years $(64.5 \%)$ with least value among patients aged $21-30$ years $(23.1 \%)$, ( $p$-value $>0.001)$. The trend in the prevalence of AmpC production and MDR resistance among the states of Northwestern Nigeria is in the following order: Sokoto>Kaduna>Katsina>Kebbi>Kano>Jigawa>Zamfara. The results from this study implied that, AmpC production is on the increase in Northwestern Nigeria and that the spread of these resistance conferring enzymes among bacterial isolates is an issue of public health concerned. Therefore, proper monitoring and surveillance for proper prevention and infection control may limit the further spread of these isolates.

Keywords: Antibiotics, Bacteria, Isolates, AmpC, Northwest, Nigeria, MDR

Seven different antibiotic discs:
\end{abstract}

\section{INTRODUCTION}

There is an increasing concerned over the rising prevalence of multidrug-resistant bacteria among patients posing greatest challenges to quality healthcare delivery with a greater burden on developing nations, accounting for a large proportion of hospital-acquired infections (Conen et al., 2015; Okoche et al., 2015; Mofolorunsho et al., 2021). Previous studies have highlighted the magnitude of infectious diseases in the human population (WHO, 2012; Andersson et al., 2014). Most of infectious diseases were treated using antibiotics. However, these antibiotics have become less effective or even ineffective; resulting in an accelerating global health emergency that is rapidly outpacing available treatment options (WHO, 2014). This problem is escalating daily in Nigeria due to antibiotic self-prescription, poor sanitary conditions even at our hospitals setting as well as ignorance (Hadi et al., 2006). The global spread of antibiotics resistance among bacterial pathogens is a serious threat to public health. It poses a threat to modern medicine with significant impact on health care cost (Pitout and Laupland, 2008). Resistant bacteria therefore lead to an increase in morbidity and mortality since it increases the risk of inappropriate therapy (Kapil, 2005; Levy et al., 2009). 
This resistance may delay and hinder treatment, resulting in complications or even death (FairandTor, 2014; Prestinaci et al., 2015). A recent report estimated that 10 million deaths will be attributed to antimicrobial resistance by 2050 and 100 trillion USD of the world's economic outputs will be lost if substantive efforts are not made to contain this threat (O'Neill, 2016; WHO, 2017).

B-lactam antibiotics are the most common treatment for bacterial infections. Production of B-lactamases is the main mechanism of bacterial resistance to these classes of antibiotics (Kotra et al., 2002). The B-lactam antibiotics are widely used antibiotics in the treatment and management of infectious diseases in Nigerian hospitals (Yusuf and Arzai, 2011). The cephalosporins were among the antibiotics daily prescribed for a wide variety of infections. Their well-known quality is widely accepted, they have lesser allergenic reactions and toxicity. Also, they are group of antibiotic with broad spectrum of activity, most of the cephalosporins prescribed daily in Nigeria, are the third generation cephalosporins particularly in the surgical departments as preferred choice for prophylaxis (Yusuf and Arzai, 2011). The high levels of chromosomal enzymes as well as plasmid - mediated Blactamases produced by several bacterial species are the major cause of cephalosporin resistance (Dancer, 2001). AmpC B-lactamases are class $C$ cephalosporinases that mediate bacterial resistance to cephalosporins and cephamycins. They also exhibit low rates of monobactam, cefepime and carbapenem hydrolysis (Fouch, 2015) and usually resist the inhibition by clavulanic acid (Agouri, 2014). Normally, AmpC is a chromosomal encoded Blactamase that is regulated by ampR gene and expressed constantly (Abdelrahman et al., 2020). Ironically, in the North-western Zone of Nigeria there is continuous and high usage of cephalosporin antibiotics with lack of proper attention to detect the enzymes which results in treatments failure. This study therefore aimed at studying the antibiotic susceptibility profiles and prevalence of AmpC among clinical bacterial isolates obtained from the Seven States of North - Western zone of Nigeria.

\section{MATERIALS AND METHODS}

\section{Collection of Clinical Isolates}

A total of one thousand (1000) clinical bacterial isolates were collected from Teaching Hospitals and Federal Medical Centers across Northwestern Nigeria. The samples were collected from sixteen different wards from
2018 to 2020. The taxonomic identities of isolates were confirmed by combinations of Gram- staining, microscopy and Biochemical tests. The colonial appearance of the bacterial isolates was also examined on CLED, McConkey and Chocolate Agar. The features observed include size, odor, and pigmentation in accordance with methods described by Cheesebrough (2010).

The isolates obtained were; Acinetobacter baumannii, Aeromonas spp, Burkholderia cepacia, Citrobacter freundii, Enterococcus faecalis, Elizabethkingia meningoseptica, Enterobacter clocae ,Escherichia coli, Klebsiella oxytoca, Klebsiella pneumoniae, Pseudomonas aeruginosa, Proteus mirabilis, Proteus vulgaris, Providence sp, Staphylococcus epidermidis, Salmonella spp, Serratia liquefaciens, Staphylococcus aureus and Vibrio cholerae.

\section{Antibiotics Susceptibility Testing}

The antibiotic susceptibility tests carried out on all the clinical isolates collected according to (CLSI 2019) guidelines. The zone diameter of each antibiotics used were measured in millimeter and interpreted as resistance, intermediate and susceptible according to CLSI guidelines (2019). Seven different antibiotic discs: Ceftriaxone $(30 \mu \mathrm{g})$, Ceftazidime $(30 \mu \mathrm{g})$,

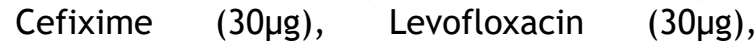

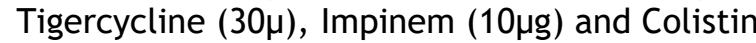
$(10 \mu \mathrm{g})$ (Oxoid, UK) were used for the antibiotic susceptibility tests with Escherichia coli ATCC 25922 strain used as the control.

\section{Screening of AmpC}

Using sterile wire loop, 4 discrete colonies were picked and emulsified in a sterile normal saline in sterile test tube. The turbidity of normal saline was matched with the turbidity of 0.5 McFarland's standard solution. Using sterile cotton swab stick, the swab stick was dipped into the suspension of the test organism and the excess fluid was removed by pressing and rotating the swab against the side of the testtube above the suspension level and it was then streaked on the surface of blood agar plate. The plate was inoculated with the suspension. Cefoxitin $(30 \mu \mathrm{g})$ discs placed at the center of the inoculated plate; the plates were inverted and incubate at $35^{\circ} \mathrm{C}$ overnight. After overnight incubation the plate was interpreted as, zone of $18 \mathrm{~mm}$ or less than $18 \mathrm{~mm}$ around the $30 \mu \mathrm{g}$ cefoxitin disk showed positive result. Mcfarland suspension of ATCC E. coli 25922 was inoculated on to the surface of Mueller Hinton

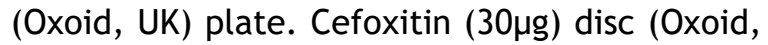
UK) was placed on the inoculated surface of the agar (Cheesbrough, 2010). 


\section{Confirmatory Test for AmpC production}

Bacterial suspensions were prepared Using sterile wire loop were 4 discreet colonies were picked and emulsified in a sterile normal saline in sterile test tube. The turbidity of normal saline was matched with the turbidity of 0.5 McFarland's standard. Sterile swab stick was dipped into the suspension of the test organism and excess fluid was removed by pressing and rotating the swab against the side of the test tube above the suspension level, then streaked on the surface of Mueller Hinton agar plate inoculated with the bacterial suspension. Using Ceftazidime $30 \mu \mathrm{g}$ disc at the center of the plate, and cefoxitin $30 \mu \mathrm{g}$, imipenem $10 \mu \mathrm{g}$ and amoxicillin-clavulanic disc $30 \mu \mathrm{g}$ at $20 \mathrm{~mm}$ distance away from ceftazidime disc. The plates were inverted and incubated at $35^{\circ} \mathrm{C}$ overnight and the plates were read for any blunting or flattening of zone of inhibition between the ceftazidime disc and any of antibiotic discs Appearance of blunting or flattening of the zone, indicates positive result for AmpC production (Gunjan et al., 2016).

Data Analysis

Statistical analysis software (SAS, 2012) was used as the statistical package. Prevalence of Cephalosprins resistant isolates was analyzed in frequency and percentages while Chi-square was used to test for the level of association at $5 \%$ level.

\section{RESULTS}

The Antibiotic susceptibility among clinical isolates obtained in Northwestern Nigeria is presented in Table 1. The result showed that, the clinical bacterial isolates were resistant to the third generation cephalosporin antibiotics (ceftazidime, ceftriaxone, cefoxitin, and cefpodoxime) commonly prescribed in the Northwestern hospitals. However, majority of the isolates showed resistance to imipenem, levofloxacin, tygercyline and colistin. Providence sp and Serratia liquefaciens were totally resistant to majority of the antibiotics used but showed activity to tigercycline and colistin respectively.

However, the result for AmpC production among the clinical isolates (Table 2 ) revealed that $51.3 \%$ of the screened isolates produced AmpC enzymes and $49.7 \%$ were Multidrug Resistance (MDR). The highest prevalence of AmpC was found in A. baumannii, Aeromonas spp, Providence sp and Serratia liquefaciens $(100 \%)$ followed by Citrobacter freundii and $E$. faecalis (66.7\%). Burkholderia capacia and Elizabethkingia meningoseptica had the least AmpC prevalence $(0.0 \%)$, with $p$-value $>0.005$
The highest prevalence of MDR among 1000 clinical bacterial isolates were found in $A$. baumanii, Aeromonas spp, Providence spp and Serratia liquefaciens (100\%) followed by Proteus mirabilis $(76.2 \%)$ and Citrobacter freundii $(66.7 \%)$, with $p$-value $<0.005$

Furthermore, these resistant isolates (Table 3) were found to occur more frequently in males (54.1\%) and higher among old aged greater than 60 years $(64.5 \%)$ followed by $41-50$ years $(63.5 \%)$. The least number of occurrences was found among those aged 21-30 years. With $p$ value $>0.005$. The highest prevalence of cephalosporins resistant isolates was found among isolated derived from Sokoto state with $73.6 \%$ occurrence followed by Kaduna $(60.1 \%)$. The least was found among isolates from Zamfara (34.2\%), with $p$-value $>0.005$, therefore, significant.

Similarly, the result for the distribution of AmpC producing isolates is shown in Table 4. The result indicated highest prevalence among isolates obtained from Emergency pediatric unit (EPU) and Female Medical ward (FMW) with $75.9 \%$ relative occurrence. The least occurrence was found in isolates from Intensive Care Unit (ICU) (25.0\%). 
Table 1: Percentage of Antibiotic Resistant Isolates Collected from Northwest Nigeria

\begin{tabular}{|c|c|c|c|c|c|c|c|c|}
\hline \multicolumn{9}{|c|}{ Resistant (\%) } \\
\hline Isolates & CAZ & CRO & CFM & FOX & LEV & TGC & $\mathrm{CT}$ & IMP \\
\hline $\begin{array}{l}\text { Acinetobacter } \\
\text { baumannii }\end{array}$ & $0(0.0)$ & $1(100.0)$ & $1(100.0)$ & $1(100.0)$ & $0(0.0)$ & $1(100.0)$ & $0(0.0)$ & $1(100.0)$ \\
\hline Aeromonas spp, & $2(66.7)$ & $3(100.0)$ & $3(100.0)$ & $2(66.7)$ & $3(100.0)$ & $1(33.3)$ & $0(0.0)$ & $0(0.0)$ \\
\hline $\begin{array}{l}\text { Burkholderia } \\
\text { cepacia }\end{array}$ & $0(0.0)$ & $0(0.0)$ & $0(0.0)$ & $0(0.0)$ & $0(0.0)$ & $0(0.0)$ & $0(0.0)$ & $0(0.0)$ \\
\hline $\begin{array}{l}\text { Citrobacter } \\
\text { freundii }\end{array}$ & $4(44.4)$ & $5(55.6)$ & $6(66.7)$ & $3(33.3)$ & $5(55.6)$ & $3(33.3)$ & $1(11.1)$ & $1(11.1)$ \\
\hline $\begin{array}{l}\text { Enterococcus } \\
\text { faecalis }\end{array}$ & $1(33.3)$ & $1(33.3)$ & $2(66.7)$ & $2(66.7)$ & $0(0.0)$ & $1(33.3)$ & $1(33.3)$ & $1(33.3)$ \\
\hline $\begin{array}{l}\text { Elizabethkingia } \\
\text { meningoseptica }\end{array}$ & $1(100.0)$ & $0(0.0)$ & $0(0.0)$ & $0(0.0)$ & $0(0.0)$ & $0(0.0)$ & $0(0.0)$ & $0(0.0)$ \\
\hline $\begin{array}{l}\text { Enterobacter } \\
\text { clocae }\end{array}$ & $5(50.0)$ & $5(50.0)$ & $6(60.0)$ & $5(50.0)$ & $4(40.0)$ & $4(40.0)$ & $2(20.0)$ & $1(10.0)$ \\
\hline Escherichia coli & $181(46.1)$ & $243(62.3)$ & $292(74.9)$ & $177(45.4)$ & $232(59.5)$ & $127(32.6)$ & $65(16.7)$ & $91(24.9)$ \\
\hline $\begin{array}{l}\text { Klebsiella } \\
\text { oxytoca }\end{array}$ & $27(67.5)$ & $22(55.0)$ & $27(67.5)$ & $21(52.5)$ & $17(42.5)$ & $9(22.5)$ & $4(10.0)$ & $5(12.5)$ \\
\hline $\begin{array}{l}\text { Klebsiella } \\
\text { pneumonia }\end{array}$ & $91(55.2)$ & $106(64.2)$ & $113(68.5)$ & $86(52.1)$ & $78(47.3)$ & $50(30.3)$ & $24(14.6)$ & $36(21.8)$ \\
\hline $\begin{array}{l}\text { Pseudomonas } \\
\text { aeruginosa }\end{array}$ & $20(41.7)$ & $29(60.4)$ & $38(79.2)$ & $26(54.2)$ & $21(43.8)$ & $17(35.4)$ & $7(14.6)$ & $15(31.3)$ \\
\hline $\begin{array}{l}\text { Proteus } \\
\text { mirabilis }\end{array}$ & $10(47.6)$ & $15(71.4)$ & $18(85.7)$ & 14(66.7) & $11(52.4)$ & $12(57.1)$ & $3(14.3)$ & $5(23.8)$ \\
\hline Proteus vulgaris & 19(42.2) & $21(46.7)$ & $36(80.0)$ & $20(44.4)$ & $17(37.8)$ & $9(20.0)$ & $11(24.4)$ & $8(17.8)$ \\
\hline Providence spp & $1(100.0)$ & $1(100.0)$ & $1(100.0)$ & 1(100.0) & $1(100.0)$ & $0(0.0)$ & $0(0.0)$ & $1(100.0)$ \\
\hline $\begin{array}{l}\text { Staphylococcus } \\
\text { epidermidis }\end{array}$ & $1(50.0)$ & $1(50.0)$ & $1(50.0)$ & $1(50.0)$ & $0(0.0)$ & $0(0.0)$ & $0(0.0)$ & $1(50.0)$ \\
\hline Salmonella spp & $7(35.0)$ & $9(45.0)$ & $8(40.0)$ & $7(35.0)$ & $5(25.0)$ & $3(15.0)$ & $3(15.0)$ & $1(5.0)$ \\
\hline $\begin{array}{l}\text { Serratia } \\
\text { liquefaciens }\end{array}$ & $1(100.0)$ & $1(100.0)$ & $1(100.0)$ & $1(100.0)$ & $1(100.0)$ & $1(100.0)$ & $0(0.0)$ & $1(100.0)$ \\
\hline $\begin{array}{l}\text { Staphylococcus } \\
\text { aureus }\end{array}$ & $83(35.3)$ & $89(37.9)$ & $125(53.2)$ & $104(44.3)$ & $83(35.3)$ & $60(25.5)$ & $33(14.0)$ & $33(14.0)$ \\
\hline Vibrio cholera & $1(33.3)$ & $1(33.3)$ & $3(100.0)$ & $2(66.7)$ & $0(0.0)$ & $0(0.0)$ & $1(33.3)$ & $0(0.0)$ \\
\hline
\end{tabular}

Key: CAZ-Ceftazidime, LEV-Levofloxacin, TGC-Tygercyline, CT-Colistin, IPM-Imipenem, CRO -Ceftrioxone CFM-Ceftizoxime, FOX-Cefoxitin.

Table 2: Prevalence of AmpC Production and MDR among Bacterial Isolates from Northwestern Nigeria

\begin{tabular}{lcccc}
\hline Isolates & \multicolumn{2}{c}{ AmpC producers } & \multicolumn{2}{c}{ MDR Bacteria } \\
& No. Examined & Positive (\%) & No. Examined & Positive (\%) \\
\hline Acinetobacter baumannii & 1 & $1(100)$ & 1 & $1(100)$ \\
Aeromonas spp, & 2 & $2(100)$ & 2 & $2(100)$ \\
Burkholderia cepacia & 1 & $0(0.0)$ & 1 & $0(0.0)$ \\
Citrobacter freundii & 9 & $6(66.7)$ & 9 & $6(66.6)$ \\
Enterococcus faecalis & 3 & $2(66.7)$ & 3 & $1(33.3)$ \\
Elizabethkingia meningoseptica & 1 & $0(0.0)$ & 1 & $0(0.0)$ \\
Enterobacter clocae & 10 & $5(50.0)$ & 10 & $6(60.0)$ \\
Escherichia coli & 390 & $248(63.6)$ & 390 & $224(57.4)$ \\
Klebsiella oxytoca & 38 & $27(71.1)$ & 38 & $20(52.6)$ \\
Klebsiella pneumonia & 167 & $111(66.5)$ & 167 & $86(51.5)$ \\
Pseudomonas aeruginosa & 47 & $29(61.7)$ & 47 & $26(55.3)$ \\
Proteus mirabilis & 21 & $17(80.9)$ & 21 & $16(76.2)$ \\
Proteus vulgaris & 44 & $26(59.1)$ & 44 & $18(40.9)$ \\
Providence spp & 1 & $1(100)$ & 1 & $1(100)$ \\
Staphylococcus epidermidis & 2 & $0(0.0)$ & 2 & $1(50.0)$ \\
Salmonella spp & 20 & $9(45.0)$ & 20 & $8(40.0)$ \\
Serratia liquefaciens & 1 & $1(100)$ & 1 & $1(100)$ \\
Staphylococcus aureus & 239 & $0(0.0)$ & 239 & $79(33.1)$ \\
Vibrio cholera & 3 & $2(66.7)$ & 3 & $1(33.3)$ \\
Total & 1000 & $513(51.3)$ & 1000 & $497(49.7)$ \\
\hline
\end{tabular}


Table 3: Distribution of AmpC Production and MDR Bacteria Based on Demographic Factor and Hospital in Northwest Nigeria

\begin{tabular}{|c|c|c|c|c|}
\hline \multirow[b]{2}{*}{ Gender } & \multicolumn{2}{|c|}{ AmpC producers } & \multicolumn{2}{|c|}{ MDR Bacteria } \\
\hline & No. Examined & Positive (\%) & No. Examined & Positive (\% \\
\hline Female & 481 & $255(53.0)$ & 481 & $233(48.4)$ \\
\hline Male & 519 & $281(54.1)$ & 519 & 264(50.9) \\
\hline Total & 1000 & $536.0(53.6)$ & 1000 & 497(49.7) \\
\hline Df & & 1 & & 1 \\
\hline$X^{2}$ & & 0.128 & & 0.588 \\
\hline P. value & & 0.721 & & 0.443 \\
\hline \multicolumn{5}{|l|}{ Age range } \\
\hline$<1$ & 53 & $30(56.6)$ & 53 & $28(52.8)$ \\
\hline $1-10$ & 127 & $73(57.5)$ & 127 & $73(63.1)$ \\
\hline $11-20$ & 54 & $30(55.6)$ & 54 & $51(57.4)$ \\
\hline $21-30$ & 269 & $124(23.1)$ & 269 & $112(41.6)$ \\
\hline $31-40$ & 245 & $120(49.0)$ & 245 & $127(51.8)$ \\
\hline $41-50$ & 115 & $73(63.5)$ & 115 & $60(52.2)$ \\
\hline $51-60$ & 75 & $46(61.3)$ & 75 & $30(40.0)$ \\
\hline$>60$ & 62 & $40(64.5)$ & 62 & 49(79.0) \\
\hline Total & 1000 & $536(53.6)$ & 1000 & $497(49.7)$ \\
\hline Df & & 7 & & 7 \\
\hline$x^{2}$ & & 18.523 & & 16.851 \\
\hline P-value & & 0.010 & & 0.018 \\
\hline \multicolumn{5}{|l|}{ Hospital } \\
\hline AKTH & 229 & $122(53.3)$ & 229 & $113(49.3)$ \\
\hline Jigawa & 141 & $58(41.1)$ & 141 & $43(30.5)$ \\
\hline Kebbi & 108 & $60(55.6)$ & 108 & $61(56.5)$ \\
\hline Katsina & 142 & $80(56.3)$ & 142 & $63(44.4)$ \\
\hline Sokoto & 121 & $89(73.6)$ & 121 & $96(79.3)$ \\
\hline \multirow[t]{2}{*}{ Zamfara } & 111 & $38(34.2)$ & 111 & $58(52.3)$ \\
\hline & 148 & $89(60.1)$ & 148 & $63(42.6)$ \\
\hline \multicolumn{5}{|l|}{ Zaria } \\
\hline Total & 1000 & $536(53.6)$ & 1000 & $497(49.7)$ \\
\hline$x^{2}$ & & 48.064 & & 70.234 \\
\hline Df & & 6 & & 6 \\
\hline P-value & & 0.000 & & 0.000 \\
\hline
\end{tabular}

Table 4: Distribution of AmpC Production and MDR Bacteria Collected from Different Hospital Wards in Northwestern Nigeria

\begin{tabular}{|c|c|c|c|c|}
\hline \multirow[b]{2}{*}{ Ward } & \multicolumn{2}{|c|}{ BlaAmpC producers } & \multicolumn{2}{|c|}{ MDR Bacteria } \\
\hline & No. Examined & Positive (\%) & No. Examined & Positive (\%) \\
\hline A\&E & 55 & $29(52.7)$ & 55 & $26(47.3)$ \\
\hline ANC & 17 & $8(47.1)$ & 17 & $6(35.3)$ \\
\hline ENDO & 2 & $1(50.0)$ & 2 & $1(50.0)$ \\
\hline ENT & 7 & $5(71.4)$ & 7 & $5(71.4)$ \\
\hline EPU & 53 & $33(75.9)$ & 53 & $31(58.5)$ \\
\hline FMW & 58 & $44(75.9)$ & 58 & $29(50.0)$ \\
\hline FSW & 30 & $13(43.3)$ & 30 & $15(50.0)$ \\
\hline GOPD & 488 & $243(49.8)$ & 488 & $230(47.1)$ \\
\hline GYNAE & 88 & $45(51.1)$ & 88 & $1(25.0)$ \\
\hline ICU & 4 & $1(25.0)$ & 4 & $1(15.0)$ \\
\hline MMW & 63 & $40(63.5)$ & 63 & $31(49.2)$ \\
\hline MSW & 67 & $35(53.7)$ & 67 & $37(55.2)$ \\
\hline Orthopedic & 3 & $1(33.3)$ & 3 & $2(66.7)$ \\
\hline PNW & 33 & $20(60.6)$ & 33 & $16(48.5)$ \\
\hline SCBU & 15 & $6(40.0)$ & 15 & $8(53.3)$ \\
\hline Urology & 17 & $11(64.7)$ & 17 & $13(76.5)$ \\
\hline Total & 1000 & $536(53.6)$ & 1000 & 497(49.7) \\
\hline
\end{tabular}




\section{DISCUSSION}

The high prevalence of cephalosporins resistance among clinical bacterial isolates reported by the present study agrees with the findings of Mofolorunsho et al. (2021) who reported similar finding among clinical bacterial isolates obtained from selected hospitals of Anyigba, Nigeria. This high prevalence can be attributed to improper diagnosis and misuse of antibiotics in the study area. The prevalence is higher among the males than females. The findings in table 3 also corroborates with that of Gashe et al. (2021) who reported high prevalence of cephalosporins resistance among isolates obtained from males. The high frequency of $\mathrm{AmpC}$ production among the isolates is in line with the work of Abdelrahman et al. (2020) who reported high frequency of ESBLs genes encoding the production of AmpC production. However, this finding contradicts that reported in pune, India by Grovera et al. (2013) where Ampc frequency was very low (14.8\%).

The increase rate of Antibiotic resistance among the Enterobacteriacea is a remarkable example of how bacteria can secure, sustain and evince new genetic information that can confer resistance from one antibiotic to several classes of antibiotics. AmpC B-lactamases are clinically important cephalosporinases encoded on the chromosomes of many Enterobacteriaceae, and also in few other gram-negative bacteria.Amp C B-lactamases can be chromosomally or plasmid mediated and they showed an enormous variation in geographic distribution worldwide. Prevalence of cephalosporinase production among K.pneumonieae in This finding is in conformity with the finding by Critchley et al. (2019) in spero therapeutic, lowa USA who reported $E$. coli as the predominant organism and resistant to third generation cephalosporins with percentage prevalence of $54.9 \%$. This is also similar to the recent finding of Sebastian et al. (2021) in Kerala, India were E.coli and $K$. pnemoniae were also found to be resistant to third generation cephalosporin indicating production of cephalosporinases. Similarly, Egbule and Odih (2020) reported AmpC among Escherichia coli, Pseudomonas aeruginosa and Klebsiella pneumonia among clinical isolates obtained from hospitalized children in Abraka and Eku communities, Delta State, Nigeria.

The overall percentage prevalence of cephalosporin resistance in seven state of Northwest Nigeria was $53.6 \%$. This finding is in contrast to that of Saarwar et al. (2019) in Pakistan where the percentage prevalence of $16 \%$ was reported. This is probably due to the low economic income of the north western region and of high population thus higher outcome. However, this study is also in conformity with the findings by Abdallah et al. (2018) in Riyadh KSA where Providence spp were found to be resistant to tigercycline and colistin and other third generation cephalosporins. Furthermore the high incidence of MDR among $E$. coli $(57.4 \%), K$. pneumonia (51.6\%) reported by the present study agrees with that of Atieh et al. (2015) who reported similar finding among isolates obtained from University Teaching Hospital,Kashan, Iran where prevalence of $50 \%$ and $46.6 \%$ were reported for $E$. coli and $K$. pneumonia respectively. Similar findings were reported in the University of Parma Italy by Andrea et al. (2019) where prevalence of $61.5 \%$ was reported in $P$. aeruginosa.

The prevalence of AmpC production and MDR in this finding among the male patients (54.1\%) and age-range (53.6\%) and (50.9\%) in male patients $(49.7 \%)$ respectively agrees with the finding of Duwadi et al.(2020) who reported high prevalence ofAmpC among males than females in Koirala Memorial Cancer Hospital, Chitwan, Nepal. This finding is also in conformity with that of Flor et al. (2018) in Aguascalients, Mexico where MDR bacteria associated more with male patients (70.8\%) than female patients (66.7\%). The high prevalence of AmpC producing bacteria isolated among bacteria the old-aged can probably be due to the rampant misuse of antibiotics by this group due to frequent complications. This may contributes to the resistance of third generation cephalosporin antibiotics. Resistance to third generation of cephalosporins in this finding were also observed among bacteria isolated from age group 41-50 $(n=73,63.5 \%)$; in this age group most patients are battling with family responsibilities, economic situations and other socioeconomic matters as well as health matters such as blood pressure, diabetes, hepatitis and other health matters. As a result of these the immunity is usually declining which gives rise to treatment failure and or longer hospital stay. This report is in agreement with that of Kiran et al.(2020) in Chitwan Nepal China were high percentage prevalence resistance to third generation cephalosporins were observed in patients aged $>60(26.8 \%)$, In male patients $(52.3 \%)$ and $(53.8 \%)$ were MDR. It is also in conformity with the study of Ramirez et al.(2018) in non-cancer patients, from Aguascalientes, Mexico were MDR phenotypically were more associated to male 
patients (83.33\%)and MDR phenotype is also more prevalent among older patients $>60$ years.

\section{CONCLUSION}

The results from this study implied that $A m p C$ production is on the increase in Northwestern Nigeria and that the spread of these resistance conferring enzymes among bacterial isolates is an issue of public health concerned. Therefore, proper monitoring and surveillance for proper prevention and infection control may limit the further spread of this Enzyme.

ACKNOWLEDGEMENTS; Special thanks are due to all Members of Ethical Committee of

\section{REFERENCES}

Abdallah. M., Alhababi. R.,Alqudah. N., Aldyyat.B., and Alharthy A., (2018). First report of carbapenems-resistance Providencia stuartii in Saudi Arabia. J. New Microbes and New infections. Vol. 26 Nov. 2018. Pages 107-109.

Abdelrahman A., Mona A., Heba. R.,Abdelhafiz. H., and Engy. A., (2020). Antibiotic resistance and Extended-spectrum Blactamase in Escherichia coli isolates from imported 1-day-old chicks, ducklings, and turkey pouts. Journal Vet World. pg 1037-1044. Epub 2020 Jun 10.Doi:10.14202/vetworld.2020.

Agouri SR., (2014). Genetic Characterization of MBL Positive Pseudomonas and Enterobacteriaceae. Cardiff University publishers (2014) pg 12-18, school of medicine, Cardiff University United Kingdom. Corpus ID; 83537201. OrcaMwe.cf.Ac.uk.

Anderson.D J.,Kelly P.,Sandra. I., BerríosTorres.D., Bratzler.W., Patchen.E., Dellinger. LG., Ann-Christine. N.,Lisa. S., Deborah. S.Y., Lisa. L., Maragakis. K., and Keith.S.,(2014): Strategies to Prevent Surgical Site Infections in Acute Care Hospitals: 2014 J Infection Control \& Hospital Epidemiology, Issue S2: A Compendium of Strategies to Prevent Healthcare-Associated Infections in Acute Care Hospitals: 2014 Updates , Vol;35pp. S66 S88September 2014 DOlhttps: //doi.org/10.1017/S0899823X 00193869.

Atieh. S.M., Babak S., Abbas. T., Ardakani. A., Moravveji. M.E., Mostafa.H.R., andMansoor.N., (2015). Multidrugresistance Escherichia coli andKlebseilla pneumoniae isolated from Patients in Kashan Iran.
Teaching hospitals and Federal Medical Centers of Kano, Kaduna, Katsina, Kebbi, Jigawa, Katsina, Sokoto, and Zamfara States. However, sincere gratitude goes to all working staffs in laboratories of Teaching and Federal Medical Centers of northwest Nigeria. Gratitude is also expressed to Nasir Doguwa, Huda Munir, Abdurrazak. I, Tukur. Panda, Bala Auna and to all those who contribute to the success of this research their effort is much appreciated. The help of Dr. Shehu of mathematics department is also acknowledged.

Jundishapur Journal of Microbiology 8(10), 2015.

Bokaeian. M., Shahram. S.Z., Morteza. S.B., and Alireza A.M.(2014). Frequency of PER, VER, SHV, TEM and CTX-M Genes in Resistant strains of Pseudomonas aureginosa producing extended spectrum B-lactamases. Jundishapur J. microbial. 2014 Dec. 8:8(1): e13783. Doi: 10.5812 ?jjm.13783. ecollection 2015 Jan.

Critchley. I. A., Cotroneo. N.,Pucci. M., and Mendes. R., (2019). The burden of antimicrobial resistance among urinary tract isolates of Escherichia coli in the United States in 2017. J PloS One2019 Dec

10;14(12)https: / / doi.org/10.1371/jour nal.plonSOne. e0220265

Dancer. S., Raeside. J., and Boothma. M., (2002). Environmental organisms from different hospital wards. British Journal of Infection Control, vol.3,4:pp.10-14. Aug 12002.

Duwadi. K., Sujan. K., Sanjib. A., and Sanjeep. S., (2020). Bacterial Ethiology of wound Exudates in Tertiary care Cancer Patients and Antibiogram of the Isolates. Infectious Diseases: Research and Treatment 13:1-8 august 2020. Doi:10,1177/1178633720952077.

Egbule.O.S., and E.E. Odih.E.E., (2020). Prevalence of Extended-Spectrum BetaLactameses (ESBLs)and Metallo-Betalactamases (MBLs) Among Healthy and Hospitalized ChildreninAbraka and Eku Communities, Delta State, Nigeria. Nigeria journal of Basic and Applied Science 9June, 2020), 28(1):07-14. DOI: http://dx.doi.org/10.4314/injbas.v28i1 .2.

Fair.R.J and Tor. Y., (2014). Antibiotics and Bacterial Resistance in $21^{\text {st }}$ Century. J 
PerspectMedicin Chem.2014; 6:25-64. Doi: 10.4137/PMC.S14459.

Flor. Y. R-C, Adriana.C.,Moreno.F., Francisco. M.D., Josee. H., and Alma. L.G.,(2018). An evaluation of Multidrug-resistant Escherichia coli isolates from Aguascalients Mexico: cross-sectional study. J. Ann.Clin. Microb 22018 July. 24; 17(1)34. Doi: 10.1186/s12941-0180286-5.

Fouch.S.,(2015). Molecular epidemiological study of extended spectrum beta lactamase (ESBL) Producing bacteria from teaching and district hospitals within Hampshire UK. https/ethos.bl.uk/orderDetails.do?uin+ uk.bl.ethos.692939.

Gashe. F., Eshetu. M., Mekidim. M., andGemechu. Z., (2018). Antimicrobial resistance Profile of Different Clinical Isolates against Third- Generation Cephalosporins. Journal of Pharmaceutics. Volume 2018, Article ID 5070742, 7pages, 2018. https://doi.org/10.1155/2018/5070742

Grovera. N., Brig. A.K., Sahnib. C., and Bhattacharya. S (2012). Therapeutic challenges of ESBLS and Ampc betalactamase producers in a tertiary care center. Medical Journal Armed Forces India (2013), 4-10, 69(1).

Gunjan.G., Vibhor.T., and Purva. M., (2014). Detection of AmpC B-Lactamases in gram-negative bacteria. Journal of laboratory physicians 6(01), 001-006, 2014.

Hadi. M., and Mohammad. R., (2008); Prevalence of extended-spectrum Blactamase-producing Escherichia coli in a tertiary care hospital in Tehran, Iran/nternational Journal of Antimicrobial Agents (2008). 13(2).

Kapil A. (2005). The challenge of Antibiotic resistance need to contemplate. The Indian journal of Medical Research. Published 1 febuary 2005; 121(2):83-91. PMID 15756040.

Kiran. D.,Sujan. K., Sanjib. A., and Sanjeep.S., (2020). Bacterial Ethiology of wound Exudates in Tertiary care Cancer Patients and Antibiogram of the Isolates. Infectious Diseases: Research and Treatment 13:1-8 august 2020. Doi:10,1177/1178633720952077.

Kotra. LP.,Haddad. J., Liano-Sotelo.B., and Shabriar. M., (2002). Aminoglycosides modified by resistance enzymes display diminished binding to the bacterial ribosomal aminocl-tRNA site. J Chemistry \& Biology 9 (4), 455-463, 2002- Elsevier.

Levy. C., de La Rocque. F., and Cohen. R., (2009). Epidemiology of pediatric bacterial meningitis in France Médecine et Maladies Infectieuses, (2009), 39(7-8)

Mofolorunsho.K. C., Hannah. O., Ocheni. R..Aminu. F., Cornelius. A., Omatola. O., and Olowonibi. 0 . (2021).Prevalence and antimicrobial susceptibility of extended-spectrum beta lactamases-producing Escherichia coli and Klebsiella pneumoniae isolated in selected hospitals of Anyigba, Nigeria. J African Health Sciences (2021)Vol. 21 No. 2 (2021)

O'Andrea. M.M., Fraziano. M.,Thaller. M.C., and Rossolili. G.M.,(2019). The urgent need for Novel Antimicrobial agents and strategies to fight Antibiotic Resistance. J. Antibiotics8 (4), 254,2019.

O'Neill..J., (2016). Tackling drug-resistance infections globally: final report and recommendations. Publisher; Government of the United Kingdom 2016. Analysis and policy Observatory (APO).

Okoche. D., Asiimwe. B.B., Katabazi.F.A., Kato. L., Najjuka.C.F .,(2015). Prevalence and Characterization of CarbapenemResistant Enterobacteriaceae Isolated from Mulago National Referral Hospital, Uganda. Journal.pubmed. PLoS One. 2015; 10(8): e0135745 2015 Aug 18;10(8):e0135745. doi: 10.1371/.

Pitout. J.J.,Laupland.K.B., and Church. D.L.,(2008). Community-onset extended-spectrum B-lactamase (ESBL) producing Escherichia coli: Importance of international travel. Journal of Infection (2008) 57(6) 441-448. ISSN: 0163-4453

Prestinaci. F., Pezzotti.P., and Pantoshi. A.(2015). Antimicrobial resistance: a global multifaceted phenomenon. J Pathog Glob Health.October, 2015;109(7):309-318.

Doi:10.1179/2047773215Y.0000000030

Ramirez.C.F., Adriana. C., Moreno.F., Francisco. M.D., Josee. H., Alma. L., and Guerrero.B., (2018). An evaluation of Multidrug-resistant Escherichia coli isolates from Aguascalients Mexico: cross-sectional study. J. Ann.Clin. Microb 22018 July. 24;17(1)34. Doi:10.1186/s12941-018-0286-5. 
Saarwar. S., Tarique. S., Waris. U., and Anwaar. A.K., (2019). Cephalosporin resistance in community acquired Spontaneous Bacterial Peritonitis. Pakistan Journal of Medical Sciences 35(1), 4,2019.

Sebastian. S., Tom. A. Annie.B., Joyal. A., and Joshy. M., (2021). Antibiotic resistance in Escherichia coli isolates from poultry environment and UTI patients in Kerala, India: A comparison study. J comparative Immunology, Microbiology and Infectious Diseases 2021), 75. DOI1 0.1016/j.cimid.2021.101614

WHO's first global report on antibiotic resistance reveals serious, worldwide threat to public health (2014). Saudi Medical Journal 2014 vol.35(7)

World Health Organization (WHO) (2014). ANTIMICROBIAL RESISTANCE Global
Report on surveillance 2014.VI.04. SECTION. Survillance of antimicrobial drug resistance in diseases-specific programmes..pg 77-169

World Health Organization (WHO) (2017). Fight Antimicrobial Resistance- it's in your hands; call from the World Health Organization for $5^{\text {th }}$ may 2017 academic. Oup

Yusuf. I., Arzai. A.H., Umah. A., Magaji. N., Salis. A., Tukur. M., Haruna. M., and Hamid. K.M., (2011). Prevalence of extended spectrum beta lactamase (ESBL) Producing Escherichia coli and Klebsiella pneumoniae in tuberculosis patients in Kano, Nigeria. 